\title{
Musculoskeletal ultrasound: taking sports medicine to the next level
}

\author{
Kimberly G Harmon, ${ }^{1}$ Francis G O'Connor ${ }^{2}$
}

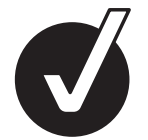

EDITOR'S

CHOICE
Ultrasound (US) technology is rapidly revolutionising the way medicine is practiced at the point of care. US is currently utilised as an integral tool in multiple non-radiologic specialties including emergency medicine, anaesthesia, neurology, general surgery, endocrinology, physical medicine, rheumatology, paediatrics and family medicine. ${ }^{1-5}$ In primary care, in particular, US instruction is routinely incorporated in residency training to facilitate prenatal care in the office, assist in vascular access in the in-patient setting and manage the trauma patient in the emergency room. ${ }^{67}$ The incorporation of some component of US training in the education of medical students and residents in the United States is now considered routine.

Musculoskeletal (MSK) US has largely been ignored in North America for the past 25 years in favour of MRI. The last 5 years, however, has seen a renaissance for MSK US in North America as we strive to catch up to our European colleagues. The reemergence of MSK US has been driven by technological advances which have made the instruments affordable, portable and practical for the office setting. US can be a cost-effective diagnostic tool in the evaluation of the patient with MSK pain ${ }^{8-10}$ and this has opened up new opportunities for both diagnostic and therapeutic interventions performed at the point of care.

\section{US FOR EVERYONE?}

The rush to utilise new technology, however, has created concerns. Who should use US? What type of training is required? How should competence be determined? Do we really need to use US for injections and procedures that have long been

\footnotetext{
${ }^{1}$ Immediate Past President American Medical Society for Sports Medicine, Hall Health Sports Medicine Clinic, University of Washington, Seattle, Washington, USA; ${ }^{2}$ President, American Medical Society for Sports Medicine, USUHS, Bethesda, Maryland, USA

Correspondence to Kimberly G Harmon, Hall Health Sports Medicine Clinic, Box 354410, University of Washington, Seattle, WA 98195, USA;

kharmon@u.washington.edu
}

performed without guidance? Is US just a vehicle for additional reimbursement or does it add to the quality and cost-effectiveness of care? These are questions that practitioners, medical societies, credentialing boards and insurers struggle to answer as technology continues to evolve.

Insurance companies limit reimbursement for MSK US to certain specialties to control costs. In fact, MSK US has the potential to be cost-saving. The average reimbursement for an MRI is close to US\$2000, while that for diagnostic MSK US is US $\$ 150$. Thus, if an US scan were to replace even an occasional MRI scan there would be cost savings. In addition, if an MSK US is done in the office, at the point of care, it can save the patient a trip back to the office to review imaging results and formulate a treatment plan. This scenario would not only be cost-effective but would also likely enhance patient satisfaction.

Concern, however, has been driven by the increasing utilisation of US which has sky rocketed as physicians have discovered its utility. Using US as an extension of physical exam in a dynamic fashion to 'see' pathology can be extremely beneficial to both the physician and the patient. US's true usefulness relates in a large part to the transducer being in the hands of the treating clinician, but, that clinician holding the transducer needs to know what they are seeing.

\section{GUIDELINES, CURRICULUMS AND COURSES}

The user-dependent nature of US has always been one of its main limitations. There is a steep learning curve to US. Just because an US unit is available doesn't mean it should be used by everyone who can reach it. The American Institute of Ultrasound Medicine addressed the question of what constituted competence in its 2009 Training Guidelines for the Performance of MSK US Examinations (http://www.aium.org/publications/ statements.aspx). The guideline resulted from input of multiple specialties with an interest in MSK US; it was ultimately endorsed by the American Medical
Society for Sports Medicine and other societies. These guidelines state that one route to competency is through a residency or fellowship that provides 'structured MSK US training'. With interest in MSK US, high among sports medicine physicians, many sports medicine fellowship programs have been working hard to provide a curriculum which will result in skilled practitioners.

The AMSSM has suggested a curriculum that residencies, fellowships and educational courses can base their training on which is presented (see page 1144). The effort was led by well-known MSK US educators and AMSSM members Jon Finoff, Jay Smith and Mark LaVallee. The curriculum consists of four parts; a didactic component, a period of direct supervision, a proctored clinical experience and recommendations for continuing education. Many sports medicine fellowships have adopted the curriculum and in some institutions it has engendered multispecialty collaboration between those with an interest in US of the MSK system: sports medicine, physical medicine and rehabilitation, rheumatology, orthopedics, radiology and anaesthesia.

In addition to the suggested curriculum, the AMSSM sponsors several courses on MSK US. There will be US preconferences prior to the annual meeting in Salt Lake City, 30 April 2010, offering both basic and advanced learning. The AMSSM Annual meeting itself (30 April 2010-4 May 2010) will feature leading national and international experts on a variety of sports medicine issues. AMSSM is also offering a basic MSK US course with the Andrews Institute in February and an advance course in Maine this spring. Visit our website for the latest details (http:// www.amssm.org/).

\section{RENAISSANCE, REVOLUTION OR RACKET?}

Diagnostic MSK US is one thing, but what about the increasing use of US for procedures? We know from $14 \%$ to $71 \%$ of injections done 'blind'-without image guidance-miss their target, ${ }^{11-14}$ and the use of US guidance significantly decreases failure rates to about 5\%. ${ }^{15-18}$ What we don't know is whether this makes a difference in clinical efficacy.

Eustace reports improved outcomes in shoulder pain in accurately placed subacromial and glenohumeral injections. ${ }^{12}$ Two studies, however, suggest that US guidance does not make a difference in long-term efficacy. ${ }^{19} 20$ These two studies examined corticosteroid joint injections in systemic 
conditions. Comparative effectiveness studies in guided versus blind injections in common conditions affecting active people such as those with osteoarthritis have not been done, nor have injections into tendons or tendon sheaths been investigated in this way. Another consideration is what, exactly, is being injected. Injected corticosteroids diffuse through tissue planes, as we see with the complications of subcutaneous fat atrophy or depigmentation. Thus, one may not need pinpoint accuracy when injecting corticosteroids. However, agents such as hyaluronic acid derivatives or platelet rich plasma (see feature and consensus paper in (see December 2010's issue of BJSM IPHP, pages 1071 and 1072)) may affect efficacy. While it is intuitive that these more expensive agents need to be correctly placed, more research needs to be done.

As clinicians strive to incorporate evolving technology into practice to improve patient care, several things are clear. Physicians who perform US should do so competently. Competency should be based on skills not arbitrarily assigned to particular specialties. The curriculum developed by AMSSM is a well-conceived and deliberated starting point to foster competency. It benefited from multidisciplinary input and true engagement across specialties (eg, radiology, rheumatology, physical medicine and rehabilitation, emergency medicine, etc.). Unlike other imaging modalities, US is best utilised at the point of care. We need be vigilant that when technology is used it improves care. Ultimately, we need to work together to make sure that we move forward in manner responsible to all-physicians, insurers and most importantly patients.

Competing interests $\mathrm{KH}$ received honoraria (totaling $\$ 3500$ ) from Sonosite (ultrasound manufacturer) for lecturing in the past.

Provenance and peer review Commissioned; not externally peer reviewed.

Accepted 20 October 2010

Br J Sports Med 2010;44:1135-1136.

doi:10.1136/bjsm.2010.080796

\section{REFERENCES}

1. Park KT, Ahn SH, Mo JH, et al. Role of core needle biopsy and ultrasonographic finding in management of indeterminate thyroid nodules. Head Neck 2010. In press.

2. Rodney WM, Deutchman ME, Hartman KJ, et al. Obstetric ultrasound by family physicians. J Fam Pract 1992;34:186-94, 197-200.

3. Walker F0, Alter KE, Boon AJ, et al. Qualifications for practitioners of neuromuscular ultrasound: position statement of the American Association of Neuromuscular and Electrodiagnostic Medicine. Muscle Nerve 2010;42:442-4.

4. Liu SS, Ngeow JE, Yadeau JT. Ultrasoundguided regional anesthesia and analgesia: a qualitative systematic review. Reg Anesth Pain Med 2009:34:47-59.

5. Levy JA, Bachur RG. Bedside ultrasound in the pediatric emergency department. Curr Opin Pediatr 2008;20:235-42.

6 Akhtar S, Theodoro D, Gaspari R, et al. Resident training in emergency ultrasound: consensus recommendations from the 2008 Council of Emergency Medicine Residency Directors Conference. Acad Emerg Med 2009;16 Suppl 2: S32-36.

7. Deutchman ME, Hahn R. Office procedures. Obstetric ultrasonography. Prim Care 1997:24:407-31.

8. Nofsinger C, Konin JG. Diagnostic ultrasound in sports medicine: current concepts and advances. Sports Med Arthrosc 2009;17:25-30.

9. Teefey SA, Hasan SA, Middleton WD, et al. Ultrasonography of the rotator cuff. A comparison of ultrasonographic and arthroscopic findings in one hundred consecutive cases. J Bone Joint Surg Am 2000;82:498-504.

10. Shahabpour $\mathbf{M}$, Kichouh $\mathbf{M}$, Laridon $\mathbf{E}$, et al. The effectiveness of diagnostic imaging methods for the assessment of soft tissue and articular disorders of the shoulder and elbow. Eur J Radiol 2008;65:194-200.

11. Esenyel C, Demirhan M, Esenyel M, et al. Comparison of four different intra-articular injection sites in the knee: a cadaver study. Knee Surg Sports Traumatol Arthrosc 2007;15:573-7.

12. Eustace JA, Brophy DP, Gibney RP, et al. Comparison of the accuracy of steroid placement with clinical outcome in patients with shoulder symptoms. Ann Rheum Dis 1997;56:59-63.

13. Heidari N, Pichler W, Grechenig S, et al. Does the anteromedial or anterolateral approach alter the rate of joint puncture in injection of the ankle?: A cadaver study. J Bone Joint Surg Br 2010;92:176-8.

14. Henkus HE, Cobben LP, Coerkamp EG, et al. The accuracy of subacromial injections: a prospective randomized magnetic resonance imaging study. Arthroscopy 2006:22:277-82.

15. Im SH, Lee SC, Park YB, et al. Feasibility of sonography for intra-articular injections in the knee through a medial patellar portal. J Ultrasound Med 2009:28:1465-70

16. Rutten MJ, Collins JM, Maresch BJ, et al. Glenohumeral joint injection: a comparative study of ultrasound and fluoroscopically guided techniques before MR arthrography. Eur Radiol 2009; 19:722-30.

17. Rutten MJ, Maresch BJ, Jager GJ, et al. Injection of the subacromial-subdeltoid bursa: blind or ultrasound-guided? Acta Orthop 2007;78:254-7.

18. Smith J, Hurdle MF, Weingarten TN. Accuracy of sonographically guided intra-articular injections in the native adult hip. J Ultrasound Med 2009;28:329-35.

19. Cunnington J, Marshall N, Hide G, et al. A randomised, double blind, controlled study of ultrasound-guided corticosteroid injection into the joint patients with inflammatory arthritis. Arthritis Rheum 2010;62:1862-9.

20. Lee HJ, Lim KB, Kim DY, et al. Randomized controlled trial for efficacy of intra-articular injection for adhesive capsulitis: ultrasonography-guided versus blind technique. Arch Phys Med Rehabil 2009;90:1997-2002. 